\title{
Traumatic retinal angiopathy resulting from chest compression by safety belt
}

\author{
G. W. HOARE \\ St. Woolos Hospital, Newport, Monmouthshire
}

The relation between crush injuries of the chest and retinal haemorrhages and exudates has been recognized since the end of the igth century (Eales, 1885). Béal (1909) and Purtscher (1910, I912) also described similar fundus lesions resulting from severe head injuries. Since that time, more than a hundred cases have been reported (e.g. by Asari, 1963; Caselli and Nuzzone, r957; Byrnes, I959; Madsen, 1965), and the condition has been described by Duke-Elder (1954) and Klein (1963).

The case described below is of interest because it followed a relatively minor compression of the chest by a seat belt of the lap-and-shoulder variety, worn by a patient driving a car when it was involved in a collision. His chest was $x$-rayed and showed no evidence of fracture and he was not sufficiently badly hurt to require admission to hospital.

The majority of cases previously described have suffered from severe injuries of the head with fracture of the skull, or severe compression injuries such as run-over injuries by a motor or other vehicle or, in recent years, compression caused by ejection from highspeed aircraft.

\section{Differential diagnosis}

Injuries remote from the eye may cause visual symptoms in several ways:

(I) GOMPRESSION INJURIES OF THORAX

There may be cyanosis and swelling of the lids and slight proptosis, and the pupil may be dilated. The characteristic fundus lesion of traumatic retinal angiopathy (Purtscher, I9I0, I912) may not appear until after a latent period of some hours or days. The following grades of severity may be recognized:

(a) White patches of exudate;

(b) Haemorrhages due to capillary rupture;

(c) Detachment of the retina.

\section{(2) FAT EMBOLISM IN THE RETINAL VESSELS}

This may occur as a complication of fractures or occasionally from soft tissue injuries. In this condition white patches and a few small haemorrhages are scattered over the retina and in the early stages the emboli can be seen.

Normally the emboli must pass through the pulmonary capillaries (unless there is a patent inter-ventricular septum) so the globules are very small. The prognosis for the eye is good. 
(3) Air embolism of the RETiNal VESSELS

This is a rare complication of chest injuries or surgery, or may occur in wounds of the jugular veins, or after a wash-out of the paranasal sinuses. The fundus appears uniformly grey with a pale disc, and the column of blood in the retinal arteries is interrupted by glittering white lines. The prognosis for the eye is good.

The fundus condition in traumatic retinal angiopathy shows some resemblance to hypertensive or albuminuric retinopathy but the condition can be distinguished by the history of injury; by the sudden onset; by the absence of hypertension or kidney disease; and also by the rapid improvement of the ocular condition with only comparatively small residual defects in the visual field.

\section{Case report}

A man aged 66 was driving a private car when it was involved in a collision. This did not directly $\frac{0}{0}$ injure his head or his eyes but he sustained minor injuries to his knee, leg, and elbow, and a small cut below his left eye. He complained that his chest was painful where it had been compressed by the safety belt. He also complained of blurred vision. An $x$-ray of the chest revealed no abnormality. He was examined in a hospital casualty department and sent home, but 3 days later he attended for an ophthalmic examination, saying that before the accident he had had excellent vision and could read small print with his reading glasses the day before the accident. After the accident, he noticed nothing abnormal in his sight until he was in the casualty department when he thought that there was a blind spot before the centre of vision of each eye.

\section{Examination}

The visual acuity in the right eye was counting fingers; in the left eye it was 6/6o. A central scotoma in each field was demonstrated with $3 / 1000$ white target within a $3^{\circ}$ circle in the left eye and a slight 10 . larger circle in the right eye. The pupils were normal and the media clear. The fundi showe slight narrowing of the arteries and nipping of veins at the arterio-venous crossings. Both fundi showed patches of retinal oedema, retinal exudates, and haemorrhages around the discs, close to the vessels and around the maculae (Figs I and 2). The blood pressure was 190/95. An $x$-ray of the skull was normal. The erythrocyte sedimentation rate was $9 \mathrm{~mm} / \mathrm{ist} \mathrm{hr}$. The blood count was normal. A biopsy of the temporal artery was normal. The Wassermann reaction was negative.

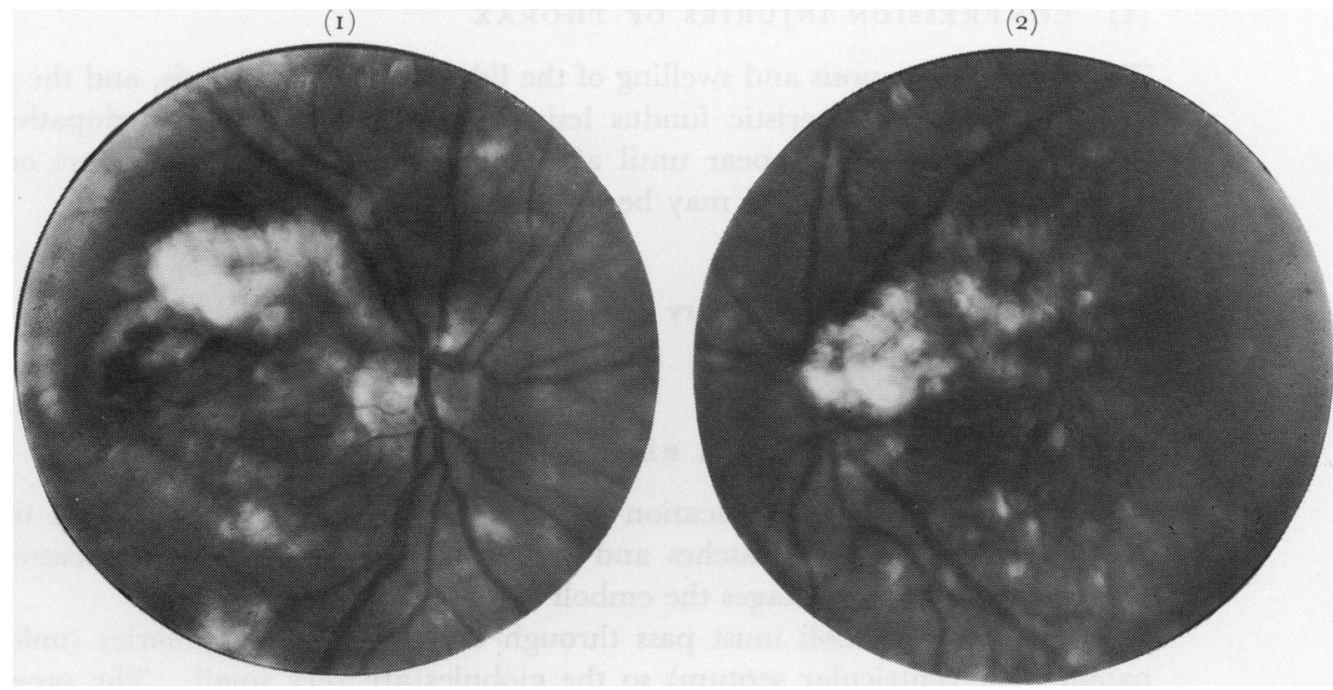

FIGS I and 2 Appearance of fundi, showing retinal oedema, exudates, and haemorrhages 


\section{Treatment}

He was given a 4-week course of prednisolone and later chymoral.

\section{Clinical course}

There was a gradual improvement in the visual acuity, until after 6 months it was $6 / 18$ corrected to $6 / 12$ in the right eye and 6/9 corrected to 6/6 partly in the left. With correction he could read $\mathrm{N}_{5}$ with difficulty. He said he could read small print more easily than large because of blind spots in the field of vision. These are demonstrable on the Bjerrum screen (Figs 3 and 4). No subsequent improvement has occurred.
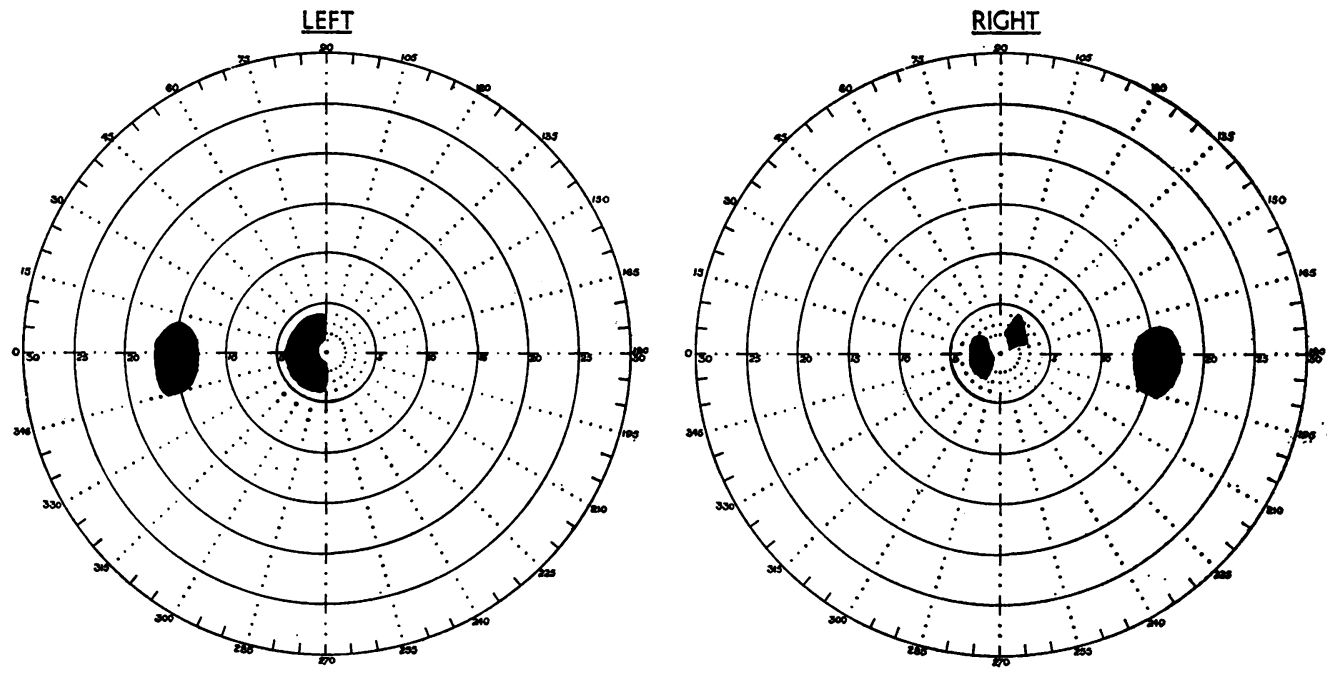

FIGS 3 and 4 Scotomata in left and right visual fields

\section{Summary}

After being involved in a collision with another car, a patient who had been wearing a seat-belt at the time was found to be suffering from traumatic retinal angiopathy (Purtscher's disease). The differential diagnosis is discussed and the progress of the condition is described.

\section{Reference}

ASARI, M. (1964) 7. clin. Ophthal., 18, 947

BÉAL, R. (1909) Ann. Oculist. (Paris), 142, 89

BYRnes, v. A. (1959) Trans. Amer. ophthal. Soc., 57, 473

CASELLI, F., and NUZzone, A. (1957) G. ital. Oftal., ro, 290

DUKE-ELDER, S. (1954) “Text book of Ophthalmology”, vol. 6, p. 6369. Kimpton, London.

EALES, H. (1885) Trans. ophthal. Soc. U.K., 5, 126

KLEIN, м. (1963) In "Modern Ophthalmology", ed. A. Sorsby, vol. 2, p. 612. Butterworths,

London

MADSEN, P. H. (1965) Acta ophthal. (Kbh.), 43, 776

MORGAN, O. GAYER (1945) Trans. ophthal. Soc. U.K., 65, 336

purtscher, o. (1910) Ber. dtsch. Ophthal. Ges., 36, 292

(1912) v. Graefes Arch. Ophthal., 82, 347 